\title{
The safety and efficacy of irreversible electroporation versus tamsulosin in the treatment of benign prostatic obstruction: study protocol and rationale for a randomized controlled trial
}

\section{Qi-Xiang Song}

Changhai Hospital https://orcid.org/0000-0001-6393-9275

\section{Biming He}

Changhai Hospital

\section{Xu Gao}

Changhai Hospital

Chuanliang Xu

Changhai Hospital

\section{Yinghao Sun}

Changhai Hospital

Haifeng Wang ( $\square$ kuohaiandrew2000@vip.sina.com )

Study protocol

Keywords: irreversible electroporation, tamsulosin, benign prostatic obstruction, lower urinary tract symptoms, maximum flow rate

Posted Date: September 19th, 2019

DOI: https://doi.org/10.21203/rs.2.14639/v1

License: (c) (1) This work is licensed under a Creative Commons Attribution 4.0 International License. Read Full License 


\section{Abstract}

Background Though transurethral resection of the prostate is still considered to be the "gold standard" procedure for benign prostatic obstruction (BPO), the reported post-operative complication rate is not uncommon. The emerging of minimally invasive focal ablative therapies provide an alternative option for patients who are dissatisfied with medical treatment yet do not willing to take the interventional procedures. Irreversible electroporation (IRE) is a novel focal therapy which can accurately ablate the target tissues with minimum damage to the surrounding structures. The application of IRE in selected patients with prostate cancer has yielded promising results, but no report on BPO has been published.

Methods/design This is a single-centered, prospective, randomized controlled trial to evaluate the effectiveness and safety of IRE in treating BPO compare with tamsulosin. We aim to recruit BPO patients who are currently taking tamsulosin but without absolute indications for surgical intervention. Eligible subjects will undergo a 3-day treatment free washout period, followed by baseline assessment. After randomized into IRE group and tamsulosin ( $0.2 \mathrm{mg}$ orally once daily) group, subjects will be followed-up for up to 24 months. The primary clinical outcome is the change in maximum flow rate from baseline at 6 months. Other assessments, including symptom questionnaires, ultrasound, prostatic specific antigen, prostate magnetic resonance image and pressure-flow study, will be carried out at different time points during follow-up. Any perception or patient-reported adverse events in both treatment arms will be documented. Data will be analyzed by a specialist who is blinded to the medical status and treatment modality in order to minimize the potential bias.

Discussion This is the first randomized controlled trial evaluating the feasibility of IRE for the treatment of BPO. The outcomes of this study will provide high level of evidence to determine its true clinical value.

\section{Background}

Transurethral resection of the prostate (TURP) is considered to be the "gold standard" procedure for the treatment of benign prostatic obstruction (BPO) with post-operative mortality and morbidity rate of $0.1 \%$ and $11.1 \%$, respectively $[1,2]$. During the past decades, some emerging minimally invasive surgical therapies, namely water vapor thermal therapy (Rezum), transurethral needle ablation (TUNA), transurethral microwaves therapy and high intensity focused ultrasound etc., have achieved not only comparable or even more superior efficacy than oral medications, but also lower complication rate in comparison with TURP. Therefore, they are becoming an alternative choice for patients with moderate to severe lower urinary tract symptoms (LUTS) who wish to give up watchful waiting or medical therapy but unwilling to accept the risks of conventional procedures [3]. However, one must note that the above mentioned modalities are all thermal based energy platform which could lead to heat damage to the surrounding healthy tissues [4].

The past a few years have yielded tremendous developments of irreversible electroporation (IRE) in the field of focal therapy for prostate cancer due to its athermal way [5]. Unlike the aforementioned methods, 
IRE can accurately ablate the target tissues and maximumly spare the neighboring structures, such as vessels, nerves and adjacent organs [6]. However, until now, there is no report on the application of IRE in patients with BPO. In this article, we provide a study protocol to evaluate the effectiveness and safety of IRE in treating BPO in comparison with tamsulosin.

\section{Methods/design Study design}

The present study is a single-centered, prospective, randomized design comparing IRE with tamsulosin with a 24-month follow-up. Male, at least 45 years of age, with predominantly bothersome voiding symptoms presenting at the clinic of Changhai Hospital will be assessed for eligibility. Patients' history, physical examination, urinalysis, ultrasonography, urodynamics and questionnaires will be evaluated by

experienced urologists. Those who fulfill the criteria will be requested to sign the informed consent before enrollment. Subsequently, subjects will be allocated to either IRE group or tamsulosin group in a 1:1 ratio using computer generated randomization lists. A 3-day treatment free run-in period will be warranted, followed by the baseline assessment. Subsequently, subjects will receive either IRE or tamsulosin ( $0.2 \mathrm{mg}$ orally once daily) treatment according to their randomized allocation status and will undergo a 24-month follow-up period. The study flow diagram was illustrated in figure 1.

\section{Biases/blinding}

Since the IRE is an invasive procedure and general anesthesia is required, neither the surgeon nor the patients will be blinded by the treatment and it will be unethical to set up a sham surgery group. We did not include a placebo medication group because $a_{1}$-adrenoceptor antagonist is the standard first-line treatment as recommended by the guidelines. To minimize the potential bias, the data processors will be blinded to the medical status and treatment modality of the subjects.

\section{Participants}

In general, men presenting bothersome voiding symptoms and with urodynamically proved BPO will be enrolled in this trial. We aim to recruit patients who are currently taking tamsulosin but without absolute indications for surgical intervention. Subjects with LUTS due to etiologies other than enlarged prostate, such as urethral stricture, tumor, stone diseases, neurogenic deficiency and anatomical abnormalities, will be considered ineligible to the study. We will also exclude subjects with severe cardiovascular diseases, active urinary tract infection and acute prostatitis. Table 1 provides a detailed list of inclusion and exclusion criteria of this trial.

\section{Interventions}


IRE will be performed by an experienced surgeon who is well trained and have previously done IRE procedures in over 60 cases. With general anesthesia and patient placed in lithotomy position, the electrodes are placed with the guidance of brachytherapy system which include transrectal ultrasound, transperineal prostate biopsy template and stepper (BK medical APS, Peabody MA, USA). The placement of the electrodes aims to ablate the hyperplastic transition zoon of the prostate. As illustrated in figure 2, four or six $18 \mathrm{G}$ electrodes (Shanghai Remedicine Co., Ltd. China), depending on the shape and volume of the prostate, will be inserted in each patient with 2-3 electrodes placed in each lobe. After insertion of the electrodes, the distances between every 2 electrodes which tend to deliver pules, will be measured in the cross-sectional plane using transrectal ultrasound. The ablation parameters between 2 electrodes are $100-150$ pulses of $5 \mu$ s plus $100-80$ pulses of $50 \mu \mathrm{s}$. The pulsed field strength of $5 \mu \mathrm{s}$ is $1500 \mathrm{v} / \mathrm{cm}$, and $50 \mu \mathrm{s}$ is $1000 \mathrm{v} / \mathrm{cm}$. After the ablation process, $50 \mathrm{ml}$ of iodophor (1:1 diluted) will be injected into the urethral to prevent urethral infection followed by inserting a transurethral catheter which was removed one week after procedure.

Subjects allocated to medication arm will be prescribed with tamsulosin monotherapy $(0.2 \mathrm{mg}$ orally once daily). In case of symptom aggravation or the presence of complications, such as bladder stone, urinary retention and repeated urinary tract infection, etc. the subjects will be considered no longer eligible to the study and should be withdrawn for further medical or surgical intervention.

\section{Outcomes}

\section{Outcome measurement}

The primary outcome will be the change in maximum flow rate $\left(Q_{\max }\right)$ from baseline at 6 months. The uroflowmetry will be performed by a single experienced urologist using the standard technique reported by the International Continence Society (ICS) [7].

The secondary outcomes are listed as follow: the changes of subjective symptoms will be measured by international prostate symptom score (IPSS) and international index of erectile function (IIEF); the post void residual volume and prostate volume will be assessed via transabdominal and transrectal ultrasound, respectively; The urodynamic parameters, including cystometric capacity, bladder compliance, maximum detrusor pressure at $\mathrm{Q}_{\max }$, voided volume, bladder outlet obstruction index and bladder contractility index etc., will be measured during pressure-flow study based on the guidelines of ICS [7]; Any perception or patient-reported adverse events in both treatment arms will be documented at all time points during follow-up. The schedule of conducting assessment during the course of study was showed in table 2.

\section{Sample size and statistical methods}

Since no published data on IRE in treating BPO is available, according to our previous experience using existing preliminary data that the mean change of $Q_{\max }$ from baseline at 6 months was $7.2 \pm 6.6 \mathrm{ml} / \mathrm{s}$ 
after IRE treatment. The sample size of tamsulosin group was calculated based on a former study indicating that the mean change of $Q_{\max }$ at 6 months was $4.4 \pm 4.8 \mathrm{ml} / \mathrm{s}$ with doxazosin treatment [8]. With $80 \%$ power, $a=0.05$ and a drop-out rate of $20 \%$, the anticipated sample size was 170 with 85 subjects in each group.

We will use intention-to-treat population to conduct the primary analysis, which means all the randomized patients, including those who receive at least one dose of a trial drug will be analyzed. Clinical outcomes will be recorded by both an encrypted computer database and hard copy backup files which can be accessed via authorized personnel only. The differences of mean change of $\mathrm{Q}_{\max }$ from baseline at 6 months between two groups will be compared by T-test. Analysis of covariance will be used to control the effect of baseline $Q_{\max }$. Subgroup analyses by age, prostate volume and symptom severity will be carried out to examine the treatment heterogeneity. The frequency of various categories of adverse events will be compared by Fisher's exact test. SAS 9.4 will be used for all analyses, and all statistical tests are twosided; $p<0.05$ is considered an indication of statistical significance.

\section{Discussion}

Benign prostatic enlargement, one of the most common cause of obstructive voiding symptoms, has an incidence of higher than $50 \%$ for males aged over 60 years [9]. While oral medications, such as a-blockers and 5a-reductase inhibitors are recommended as first-line therapies to men with moderate-to-severe LUTS, surgical procedures are required if symptom progression or complications occur [1]. Although TURP is by far the "gold standard" procedure, it has relatively high complications, like TUR syndrome, urethral stricture, bleeding and so on. Fortunately, the emerging of new energy platform gives rise to a range of novel ablation methods which are more effective than medications and with lower complication rate compared to conventional endoscopic procedures. However, those energy therapies are all based on thermal mechanisms which may accidentally damage the surrounding functional structures due to heat conduction effects [10]. A prospective study reported that although Rezum system significantly reduced IPSS and increased $Q_{\max }$ at 1 year, the total adverse event were reported in $69.2 \%$ of subjects [11]. A systematic review on TUNA reported the incidence rate of hematuria, urinary retention, dysuria and irritative symptoms were $38 \%, 23 \%, 14 \%$ and $10 \%$, respectively [12].

In contrast, IRE is based on the principle of generating electric pulses to create nanoscale defects (also termed "nanopores") in the cell membrane. Beyond a certain threshold, the nanopores become permanent and lead to disturbed homeostasis and cell death $[4,6]$. Therefore, it is not a thermal ablation technique and have the potential to provide a full protection of the surrounding nerves and vessels. In a pilot study, IRE has been successfully applied in the treatment of prostate cancer with a normal urinary function reported in $88 \%$ and $94 \%$ of the patients at 6 and 12 months follow-up, respectively [13].

As the first randomized controlled trial evaluating the feasibility of IRE for the treatment of BPO, despite with some challenges, we chose the well-established standard first-line medicine tamsulosin as the control group in order to provide high level of evidence to determine the true clinical value of IRE. Though 
with current design, some potential limitations should be addressed. To begin with, all IRE procedures will be done by one surgeon in a single center and therefore possible bias may exist. However, since ours is the first and currently the only urological center in China performing IRE surgery to patients with BPO with well-developed skills, the result of this pilot study could possibly encourage its use in expanded areas and offer a chance for future multicenter studies. Besides, the follow-up period of 24 months only provides mid-term outcomes regarding the effectiveness and safety of IRE. Little is known about the long-term symptom recurrence rate and complications, although they have been well studied with a-blockers or/and 5ARIs therapy $[14,15]$. Furthermore, since neither the surgeon nor the patients will be blinded, and no sham surgery or sham medication group was involved, potential bias to the treatment options may exist. To minimize this weakness, we chose $Q_{\max }$ which is an objective parameter as our primary outcome. Meanwhile, the uroflowmetry assessment and data analysis will be performed in a blinded manner. Nonetheless, even with the above shortcomings in our design, we believe that the result of this trial can provide robust evidence to validate the use of IRE in clinical management of BPO.

\section{Trial Status}

All research staff members have approved the study design and have went through a step by step protocol training program to ensure the consistency throughout the trial. The first subject was randomized in November 2018. The recruitment was anticipated to complete within 2 years. Current protocol version 2.0, October 2018.

\section{Abbreviations}

BPO: benign prostatic obstruction

ICS: International Continence Society

IIEF: international index of erectile function

IPSS: international prostate symptom score

IRE: irreversible electroporation

TUNA: transurethral needle ablation

TURP: transurethral resection of the prostate

LUTS: lower urinary tract symptoms

\section{Declarations}

\section{Ethics approval and consent to participate}


The study protocol has been approved by the ethics committee boards of Shanghai Changhai Hospital (approval number: CHEC2018-125). The trial will be conducted following the Standard Protocol Items: Recommendations for Interventional Trials (SPIRIT). The registration information can be accessed on ClinicalTrials.gov (ID: NCT03448510). Written informed consent will be obtained from all patients for participation in the trial and prior to intervention.

\section{Consent for publication}

Not applicable.

\section{Availability of data and materials}

Not applicable.

\section{Competing interests}

The authors declare that they have no competing interests.

\section{Funding}

This work was supported by Shanghai Remedicine Co., Ltd. Company, National Natural Science Foundation of China (NO. 81500579) and Translational Medicine Research Project of Naval Medical University (NO. 2017JZ44)

\section{Authors' contributions}

QXS, YS and HW designed the study. BH, XG and CX revised the protocol. QXS completed the trial registration. HF was responsible for patient recruitment. $\mathrm{BH}$ assisted $\mathrm{HW}$ in performing the procedures. QXS performed the pressure-flow study and uroflowmetry. The manuscript was drafted by QXS and revised by $\mathrm{HW}, \mathrm{YS}, \mathrm{BH}, \mathrm{XG}$ and $\mathrm{CX}$. QXS and $\mathrm{BH}$ were responsible for data collection and statistical analysis. All authors read and approved the final manuscript.

\section{Acknowledgements}

The authors gratefully acknowledge Ms. Yiru Hao for her technical support on urodynamic studies.

\section{References}


1. Gravas S, Cornu JN, Drake MJ, Gacci M, Gratzke C, Herrmann TRW et al. EAU guidelines on management of non-neurogenic male lower urinary tract symptoms (LUTS), incl. benign prostatic obstruction (BPO). 2018.

2. Reich O, Gratzke C, Bachmann A, Seitz M, Schlenker B, Hermanek P et al. Morbidity, mortality and early outcome of transurethral resection of the prostate: a prospective multicenter evaluation of 10,654 patients. J Urol. 2008;180(1):246-9. doi:10.1016/j.juro.2008.03.058.

3. McVary KT, Roehrborn CG. Three-Year Outcomes of the Prospective, Randomized Controlled Rezum System Study: Convective Radiofrequency Thermal Therapy for Treatment of Lower Urinary Tract Symptoms Due to Benign Prostatic Hyperplasia. Urology. 2018;111:1-9. doi:10.1016/j.urology.2017.10.023.

4. Valerio M, Ahmed HU, Emberton M, Lawrentschuk N, Lazzeri M, Montironi R et al. The role of focal therapy in the management of localised prostate cancer: a systematic review. Eur Urol. 2014;66(4):732-51. doi:10.1016/j.eururo.2013.05.048.

5. Ting F, Tran M, Bohm M, Siriwardana A, Van Leeuwen PJ, Haynes AM et al. Focal irreversible electroporation for prostate cancer: functional outcomes and short-term oncological control. Prostate Cancer Prostatic Dis. 2016;19(1):46-52. doi:10.1038/pcan.2015.47.

6. Wagstaff PG, Buijs M, van den Bos W, de Bruin DM, Zondervan PJ, de la Rosette JJ et al. Irreversible electroporation: state of the art. Onco Targets Ther. 2016;9:2437-46. doi:10.2147/OTT.S88086.

7. Abrams P, Cardozo L, Fall M, Griffiths D, Rosier P, Ulmsten U et al. The standardisation of terminology of lower urinary tract function: report from the Standardisation Sub-committee of the International Continence Society. Neurourol Urodyn. 2002;21(2):167-78.

8. Gupta N, Rogers T, Holland B, Helo S, Dynda D, McVary KT. Three-Year Treatment Outcomes of Water Vapor Thermal Therapy Compared to Doxazosin, Finasteride and Combination Drug Therapy in Men with Benign Prostatic Hyperplasia: Cohort Data from the MTOPS Trial. J Urol. 2018;200(2):405-13. doi:10.1016/j.juro.2018.02.3088.

9. Roehrborn CG. Male lower urinary tract symptoms (LUTS) and benign prostatic hyperplasia (BPH). Med Clin North Am. 2011;95(1):87-100. doi:10.1016/j.mcna.2010.08.013.

10. Patelli G, Ranieri A, Paganelli A, Mauri G, Pacella CM. Transperineal Laser Ablation for Percutaneous Treatment of Benign Prostatic Hyperplasia: A Feasibility Study. Cardiovasc Intervent Radiol. 2017;40(9):1440-6. doi:10.1007/s00270-017-1662-9.

11. Dixon C, Cedano ER, Pacik D, Vit V, Varga G, Wagrell L et al. Efficacy and Safety of Rezum System Water Vapor Treatment for Lower Urinary Tract Symptoms Secondary to Benign Prostatic Hyperplasia. Urology. 2015;86(5):1042-7. doi:10.1016/j.urology.2015.05.046.

12. Bouza C, Lopez T, Magro A, Navalpotro L, Amate JM. Systematic review and meta-analysis of Transurethral Needle Ablation in symptomatic Benign Prostatic Hyperplasia. BMC Urol. 2006;6:14. doi:10.1186/1471-2490-6-14.

13. Murray KS, Ehdaie B, Musser J, Mashni J, Srimathveeravalli G, Durack JC et al. Pilot Study to Assess Safety and Clinical Outcomes of Irreversible Electroporation for Partial Gland Ablation in Men with 
Prostate Cancer. J Urol. 2016;196(3):883-90. doi:10.1016/j.juro.2016.02.2986.

14. McConnell JD, Roehrborn CG, Bautista OM, Andriole GL, Jr., Dixon CM, Kusek JW et al. The long-term effect of doxazosin, finasteride, and combination therapy on the clinical progression of benign prostatic hyperplasia. N Engl J Med. 2003;349(25):2387-98. doi:10.1056/NEJMoa030656.

15. Roehrborn CG, Siami P, Barkin J, Damiao R, Major-Walker K, Nandy I et al. The effects of combination therapy with dutasteride and tamsulosin on clinical outcomes in men with symptomatic benign prostatic hyperplasia: 4-year results from the CombAT study. Eur Urol. 2010;57(1):123-31. doi:10.1016/j.eururo.2009.09.035.

\section{Tables}

Table 1. The inclusion and exclusion criteria used in this trial.

\begin{tabular}{|c|c|c|c|c|c|c|}
\hline Study procedures & Baseline & 1 month & 3 months & 6 months & 12 months & 24 months \\
\hline 1. Informed consent & $\sqrt{ }$ & & & & & \\
\hline 2. Basic information & $\sqrt{ }$ & & & & & \\
\hline 3. History and physical examnination & $\sqrt{ }$ & & & & & \\
\hline 4. Blood test & $\sqrt{ }$ & & & & & \\
\hline 5. Urinary tract ultrasound & $\sqrt{ }$ & & & $\sqrt{ }$ & $\sqrt{ }$ & $\sqrt{ }$ \\
\hline 6. Prostatic specific antigen & $\sqrt{ }$ & & & $\sqrt{ }$ & $\sqrt{ }$ & $\sqrt{ }$ \\
\hline 7. Pressure-flow study & $\sqrt{ }$ & & & $\sqrt{ }$ & $\sqrt{ }$ & $\sqrt{ }$ \\
\hline 8. Prostate MRI & $\sqrt{ }$ & & $\sqrt{ }$ & & $\sqrt{ }$ & $\sqrt{ }$ \\
\hline 9. Transrectal ultrasound & $\sqrt{ }$ & & $\sqrt{ }$ & & $\sqrt{ }$ & $\sqrt{ }$ \\
\hline 10. Urinalysis & $\sqrt{ }$ & & $\sqrt{ }$ & $\sqrt{ }$ & $\sqrt{ }$ & $\sqrt{ }$ \\
\hline 11. Urinary flow study & $\sqrt{ }$ & & $\sqrt{ }$ & $\sqrt{ }$ & $\sqrt{ }$ & $\sqrt{ }$ \\
\hline 12. Post void residual & $\sqrt{ }$ & & $\sqrt{ }$ & $\sqrt{ }$ & $\sqrt{ }$ & $\sqrt{ }$ \\
\hline 13. IPSS + QoL questionnaires & $\sqrt{ }$ & $\sqrt{ }$ & $\sqrt{ }$ & $\sqrt{ }$ & $\sqrt{ }$ & $\sqrt{ }$ \\
\hline 14. IIEF questionnaires & $\sqrt{ }$ & $\sqrt{ }$ & $\sqrt{ }$ & $\sqrt{ }$ & $\sqrt{ }$ & $\sqrt{ }$ \\
\hline 15. Treatment related adverse effects & & $\sqrt{ }$ & $\sqrt{ }$ & $\sqrt{ }$ & $\sqrt{ }$ & $\sqrt{ }$ \\
\hline
\end{tabular}


Table 2. The study timeline.

The SPIRIT checklist

Page 10/16 


\begin{tabular}{lclc}
\hline Title & $\# 1$ & $\begin{array}{l}\text { Descriptive title identifying the study design, } \\
\text { population, interventions, and, if applicable, trial } \\
\text { acronym }\end{array}$ & 1 \\
$\begin{array}{l}\text { Trial } \\
\text { registration }\end{array}$ & \#2a & $\begin{array}{l}\text { Trial identifier and registry name. If not yet } \\
\text { registered, name of intended registry }\end{array}$ & 3 \\
$\begin{array}{l}\text { Trial } \\
\text { registration: } \\
\text { data set }\end{array}$ & \#2b & $\begin{array}{l}\text { All items from the World Health Organization Trial } \\
\text { Registration Data Set }\end{array}$ & $\mathrm{n} / \mathrm{a}$ \\
\hline
\end{tabular}

Protocol

\#3 Date and version identifier

version

Funding

\#4

Sources and types of financial, material, and other

$13-14$

Roles and \#5a support

responsibilities:

contributorship

Roles and responsibilities:

\#5

Names,

affilia

filiation

Name and contact information for the trial sponsor n/a

sponsor

contact

information

Roles and

responsibilities:

\#5c Role of study sponsor and funders, if any, in study

$\mathrm{n} / \mathrm{a}$

sponsor and

funder

design; collection, management, analysis, and

interpretation of data; writing of the report; and the decision to submit the report for publication, including

whether they will have ultimate authority over any of

these activities

Roles and
responsibilities:
committees

\#5d

Composition, roles, and responsibilities of the

$\mathrm{n} / \mathrm{a}$

coordinating centre, steering committee, endpoint

adjudication committee, data management team, and

other individuals or groups overseeing the trial, if

applicable (see Item 21a for data monitoring committee)

Background
and rationale
Background
and rationale:
choice of
comparators

\#6a

Description of research question and justification for

undertaking the trial, including summary of relevant

studies (published and unpublished) examining

benefits and harms for each intervention

\#6b Explanation for choice of comparators

4

Objectives

Trial design

\#7 Specific objectives or hypotheses

\#8 Description of trial design including type of trial (eg parallel group, crossover, factorial, single group),

Study setting \#9 Description of study settings (eg, community clinic, academic hospital) and list of countries where data will be collected. Reference to where list of study sites

Eligibility

criteria

\#10

Interventions: \#11a description

Interventions: \#11b Criteria for discontinuing or modifying allocated allocation ratio, and framework (eg, superiority, equivalence, non-inferiority, exploratory) can be obtained

Inclusion and exclusion criteria for participants. If applicable, eligibility criteria for study centres and individuals who will perform the interventions (eg, surgeons, psychotherapists)

4

5

5

6

5-6

allow replication, including how and when they will be administered

Page $11 / 16$ 
modifications

\begin{tabular}{|c|c|c|c|}
\hline $\begin{array}{l}\text { Interventions: } \\
\text { adherance }\end{array}$ & $\# 11 \mathrm{c}$ & $\begin{array}{l}\text { Strategies to improve adherence to intervention } \\
\text { protocols, and any procedures for monitoring } \\
\text { adherence (eg, drug tablet return; laboratory tests) }\end{array}$ & $\mathrm{n} / \mathrm{a}$ \\
\hline $\begin{array}{l}\text { Interventions: } \\
\text { concomitant } \\
\text { care }\end{array}$ & \#11d & $\begin{array}{l}\text { Relevant concomitant care and interventions that are } \\
\text { permitted or prohibited during the trial }\end{array}$ & 7 \\
\hline Outcomes & \#12 & $\begin{array}{l}\text { Primary, secondary, and other outcomes, including } \\
\text { the specific measurement variable (eg, systolic blood } \\
\text { pressure), analysis metric (eg, change from baseline, } \\
\text { final value, time to event), method of aggregation (eg, } \\
\text { median, proportion), and time point for each outcome. } \\
\text { Explanation of the clinical relevance of chosen } \\
\text { efficacy and harm outcomes is strongly recommended }\end{array}$ & $7-8$ \\
\hline $\begin{array}{l}\text { Participant } \\
\text { timeline }\end{array}$ & \#13 & $\begin{array}{l}\text { Time schedule of enrolment, interventions (including } \\
\text { any run-ins and washouts), assessments, and visits for } \\
\text { participants. A schematic diagram is highly } \\
\text { recommended (see Figure) }\end{array}$ & 8 \\
\hline Sample size & \#14 & $\begin{array}{l}\text { Estimated number of participants needed to achieve } \\
\text { study objectives and how it was determined, including } \\
\text { clinical and statistical assumptions supporting any } \\
\text { sample size calculations }\end{array}$ & 8 \\
\hline Recruitment & \#15 & $\begin{array}{l}\text { Strategies for achieving adequate participant } \\
\text { enrolment to reach target sample size }\end{array}$ & $\mathrm{n} / \mathrm{a}$ \\
\hline $\begin{array}{l}\text { Allocation: } \\
\text { sequence } \\
\text { generation }\end{array}$ & \#16a & $\begin{array}{l}\text { Method of generating the allocation sequence (eg, } \\
\text { computer-generated random numbers), and list of any } \\
\text { factors for stratification. To reduce predictability of a } \\
\text { random sequence, details of any planned restriction } \\
\text { (eg, blocking) should be provided in a separate } \\
\text { document that is unavailable to those who enrol } \\
\text { participants or assign interventions }\end{array}$ & 5 \\
\hline $\begin{array}{l}\text { Allocation } \\
\text { concealment } \\
\text { mechanism }\end{array}$ & \#16b & $\begin{array}{l}\text { Mechanism of implementing the allocation sequence } \\
\text { (eg, central telephone; sequentially numbered, } \\
\text { opaque, sealed envelopes), describing any steps to } \\
\text { conceal the sequence until interventions are assigned }\end{array}$ & $\mathrm{n} / \mathrm{a}$ \\
\hline $\begin{array}{l}\text { Allocation: } \\
\text { implementation }\end{array}$ & \#16c & $\begin{array}{l}\text { Who will generate the allocation sequence, who will } \\
\text { enrol participants, and who will assign participants to } \\
\text { interventions }\end{array}$ & $\mathrm{n} / \mathrm{a}$ \\
\hline $\begin{array}{l}\text { Blinding } \\
\text { (masking) }\end{array}$ & $\# 17 a$ & $\begin{array}{l}\text { Who will be blinded after assignment to interventions } \\
\text { (eg, trial participants, care providers, outcome } \\
\text { assessors, data analysts), and how }\end{array}$ & 5 \\
\hline $\begin{array}{l}\text { Blinding } \\
\text { (masking): } \\
\text { emergency } \\
\text { unblinding }\end{array}$ & \#17b & $\begin{array}{l}\text { If blinded, circumstances under which unblinding is } \\
\text { permissible, and procedure for revealing a } \\
\text { participant's allocated intervention during the trial }\end{array}$ & $\mathrm{n} / \mathrm{a}$ \\
\hline $\begin{array}{l}\text { Data collection } \\
\text { plan }\end{array}$ & \#18a & $\begin{array}{l}\text { Plans for assessment and collection of outcome, } \\
\text { baseline, and other trial data, including any related } \\
\text { processes to promote data quality (eg, duplicate } \\
\text { measurements, training of assessors) and a } \\
\text { description of study instruments (eg, questionnaires, } \\
\text { laboratory tests) along with their reliability and } \\
\text { validity, if known. Reference to where data collection } \\
\text { forms can be found, if not in the protocol }\end{array}$ & $6-7$ \\
\hline $\begin{array}{l}\text { Data collection } \\
\text { plan: retention }\end{array}$ & \#18b & $\begin{array}{l}\text { Plans to promote participant retention and complete } \\
\text { follow-up, including list of any outcome data to be } \\
\text { collected for participants who discontinue or deviate } \\
\text { from intervention protocols }\end{array}$ & $\mathrm{n} / \mathrm{a}$ \\
\hline
\end{tabular}

interventions for a given trial participant (eg, drug dose change in response to harms, participant request, or improving / worsening disease) protocols, and any procedures for monitoring Relevant concomitant care and interventions that are permitted or prohibited during the trial

Primary, secondary, and other outcomes, including pressure), analysis metric (eg, change from baseline, final value, time to event), method of aggregation (eg, median, proportion), and time point for each outcome. Explanation of the clinical relevance of chosen explacy and harm outcomes is strongly recommended any run-ins and washouts), assessments, and visits for participants. A schematic diagram is highly recommended (see Figure)

Estumated number of participants n clinical and statistical assumptions supporting any sample size calculations

Strategies for achieving adequate particip

Method of generating the allocation sequence (eg, computer-generated random numbers), and list of any factors for stratification. To reduce predictability of a random sequence, details of any planned restriction (eg, blocking) should be provided in a separate document that is unavailable to those who enrol

(eg, central telephone; sequentially numbered, opaque, sealed envelopes), describing any steps to conceal the sequence until interventions are assigned

enrol participants, and who will assign participants to assessors, data analysts), and how

permissible, and procedure for revealing a participant's allocated intervention during the trial

Plans for assessment and collection of outcome, baseline, and other trial data, including any related measurements, training of assessors) and a description of study instruments (eg, questionnaires, laboratory tests) along with their reliability and validity, if known. Reference to where data collection forms can be found, if not in the protocol follow-up, including list of any outcome data to be from intervention protocols (eg, trial participants, care providers, outcome 
Data management

\#19

Plans for data entry, coding, security, and storage, including any related processes to promote data quality (eg, double data entry; range checks for data values). Reference to where details of data management procedures can be found, if not in the protocol

Statistics: outcomes \#20a

Statistical methods for analysing primary and secondary outcomes. Reference to where other details of the statistical analysis plan can be found, if not in the protocol

Statistics: additional analyses

Statistics: analysis population and missing data

Data monitoring:

formal committee

\begin{tabular}{|c|c|c|c|}
\hline $\begin{array}{l}\text { Data } \\
\text { monitoring: } \\
\text { interim } \\
\text { analysis }\end{array}$ & \#21b & $\begin{array}{l}\text { Description of any interim analyses and stopping } \\
\text { guidelines, including who will have access to these } \\
\text { interim results and make the final decision to } \\
\text { terminate the trial }\end{array}$ & $\mathrm{n} / \mathrm{a}$ \\
\hline Harms & \#22 & $\begin{array}{l}\text { Plans for collecting, assessing, reporting, and } \\
\text { managing solicited and spontaneously reported } \\
\text { adverse events and other unintended effects of trial } \\
\text { interventions or trial conduct }\end{array}$ & 7 \\
\hline Auditing & \#23 & $\begin{array}{l}\text { Frequency and procedures for auditing trial conduct, } \\
\text { if any, and whether the process will be independent } \\
\text { from investigators and the sponsor }\end{array}$ & $\mathrm{n} / \mathrm{a}$ \\
\hline $\begin{array}{l}\text { Research } \\
\text { ethics approval }\end{array}$ & \#24 & $\begin{array}{l}\text { Plans for seeking research ethics committee / } \\
\text { institutional review board (REC / IRB) approval }\end{array}$ & 14 \\
\hline $\begin{array}{l}\text { Protocol } \\
\text { amendments }\end{array}$ & \#25 & $\begin{array}{l}\text { Plans for communicating important protocol } \\
\text { modifications (eg, changes to eligibility criteria, } \\
\text { outcomes, analyses) to relevant parties (eg, } \\
\text { investigators, REC / IRBs, trial participants, trial } \\
\text { registries, journals, regulators) }\end{array}$ & $\mathrm{n} / \mathrm{a}$ \\
\hline $\begin{array}{l}\text { Consent or } \\
\text { assent }\end{array}$ & \#26a & $\begin{array}{l}\text { Who will obtain informed consent or assent from } \\
\text { potential trial participants or authorised surrogates, } \\
\text { and how (see Item 32) }\end{array}$ & 5 \\
\hline $\begin{array}{l}\text { Consent or } \\
\text { assent: } \\
\text { ancillary } \\
\text { studies }\end{array}$ & \#26b & $\begin{array}{l}\text { Additional consent provisions for collection and use of } \\
\text { participant data and biological specimens in ancillary } \\
\text { studies, if applicable }\end{array}$ & $\begin{array}{l}\text { n/a } \\
\text { (has } \\
\text { been } \\
\text { included } \\
\text { in the } \\
\text { informed } \\
\text { consent) }\end{array}$ \\
\hline Confidentiality & \#27 & $\begin{array}{l}\text { How personal information about potential and } \\
\text { enrolled participants will be collected, shared, and } \\
\text { maintained in order to protect confidentiality before, } \\
\text { during, and after the trial }\end{array}$ & $\begin{array}{l}\mathrm{n} / \mathrm{a} \\
\text { (has } \\
\text { been } \\
\text { included } \\
\text { in the }\end{array}$ \\
\hline
\end{tabular}

Harms \#22

\#21b Methods for any additional analyses (eg, subgroup and adjusted analyses)

\#20c Definition of analysis population relating to protocol non-adherence (eg, as randomised analysis), and any statistical methods to handle missing data (eg, multiple imputation)

\#21a Composition of data monitoring committee (DMC); n/a summary of its role and reporting structure; statement of whether it is independent from the sponsor and competing interests; and reference to where further details about its charter can be found, if not in the protocol. Alternatively, an explanation of why a DMC is not needed 


\begin{tabular}{|c|c|c|c|}
\hline $\begin{array}{l}\text { Declaration of } \\
\text { interests }\end{array}$ & \#28 & $\begin{array}{l}\text { Financial and other competing interests for principal } \\
\text { investigators for the overall trial and each studv site }\end{array}$ & 9 \\
\hline Data access & \#29 & $\begin{array}{l}\text { Statement of who will have access to the final trial } \\
\text { dataset, and disclosure of contractual agreements } \\
\text { that limit such access for investigators }\end{array}$ & 9 \\
\hline $\begin{array}{l}\text { Ancillary and } \\
\text { post trial care }\end{array}$ & \#30 & $\begin{array}{l}\text { Provisions, if any, for ancillary and post-trial care, } \\
\text { and for compensation to those who suffer harm from } \\
\text { trial participation }\end{array}$ & 9 \\
\hline $\begin{array}{l}\text { Dissemination } \\
\text { policy: trial } \\
\text { results }\end{array}$ & \#31a & $\begin{array}{l}\text { Plans for investigators and sponsor to communicate } \\
\text { trial results to participants, healthcare professionals, } \\
\text { the public, and other relevant groups (eg, via } \\
\text { publication, reporting in results databases, or other } \\
\text { data sharing arrangements), including any publication } \\
\text { restrictions }\end{array}$ & $\mathrm{n} / \mathrm{a}$ \\
\hline $\begin{array}{l}\text { Dissemination } \\
\text { policy: } \\
\text { authorship }\end{array}$ & \#31b & $\begin{array}{l}\text { Authorship eligibility guidelines and any intended use } \\
\text { of professional writers }\end{array}$ & $\mathrm{n} / \mathrm{a}$ \\
\hline $\begin{array}{l}\text { Dissemination } \\
\text { policy: } \\
\text { reproducible } \\
\text { research }\end{array}$ & \#31c & $\begin{array}{l}\text { Plans, if any, for granting public access to the full } \\
\text { protocol, participant-level dataset, and statistical code }\end{array}$ & $\mathrm{n} / \mathrm{a}$ \\
\hline $\begin{array}{l}\text { Informed } \\
\text { consent } \\
\text { materials }\end{array}$ & \#32 & $\begin{array}{l}\text { Model consent form and other related documentation } \\
\text { given to participants and authorised surrogates }\end{array}$ & $\begin{array}{l}\mathrm{n} / \mathrm{a} \\
\text { (the } \\
\text { consent } \\
\text { form is } \\
\text { in } \\
\text { Chinese) }\end{array}$ \\
\hline $\begin{array}{l}\text { Biological } \\
\text { specimens }\end{array}$ & \#33 & $\begin{array}{l}\text { Plans for collection, laboratory evaluation, and } \\
\text { storage of biological specimens for genetic or } \\
\text { molecular analysis in the current trial and for future } \\
\text { use in ancillary studies, if applicable }\end{array}$ & $\mathrm{n} / \mathrm{a}$ \\
\hline
\end{tabular}

\section{Figures}




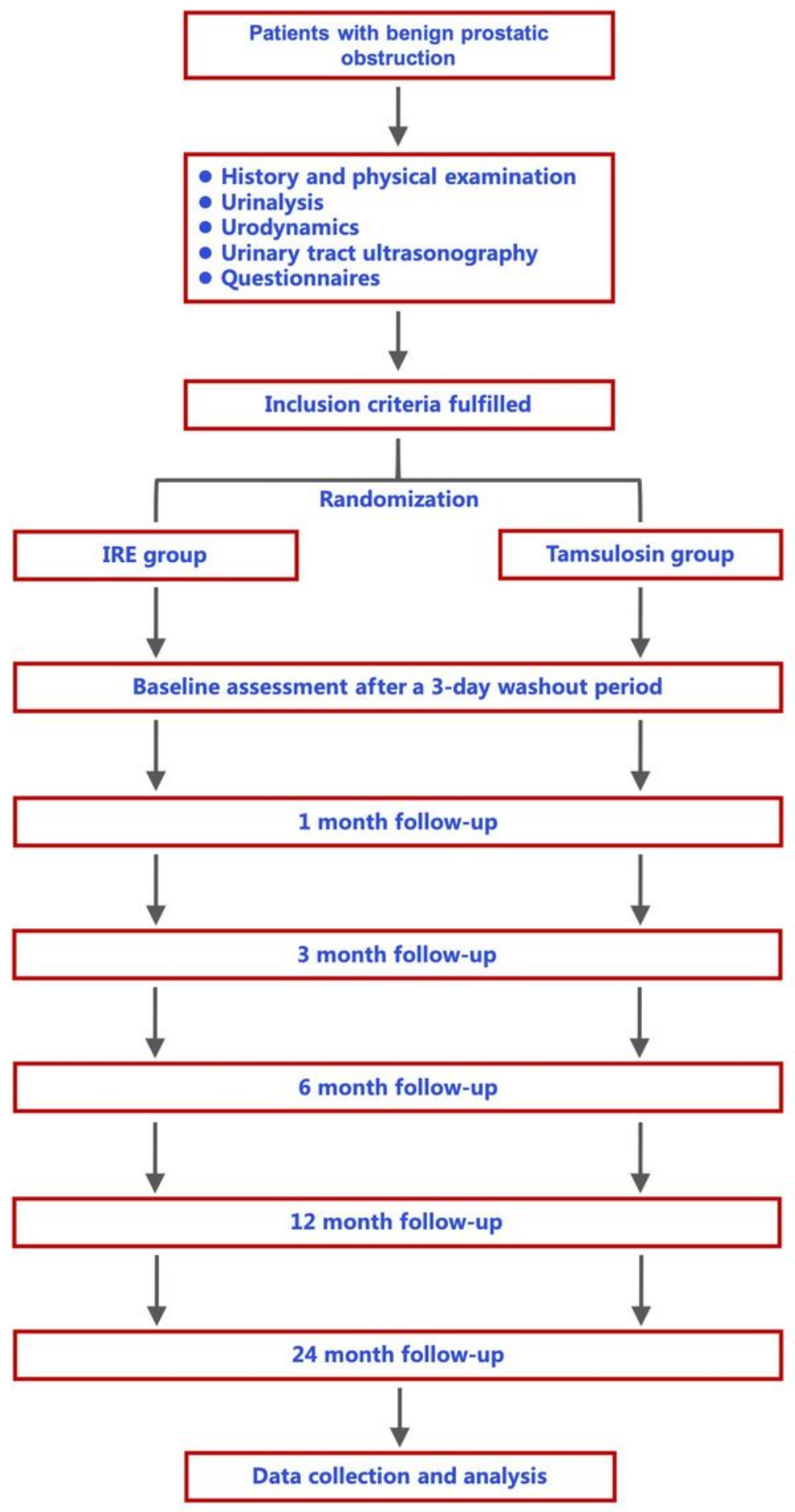

\section{Figure 1}

The study flow diagram. 

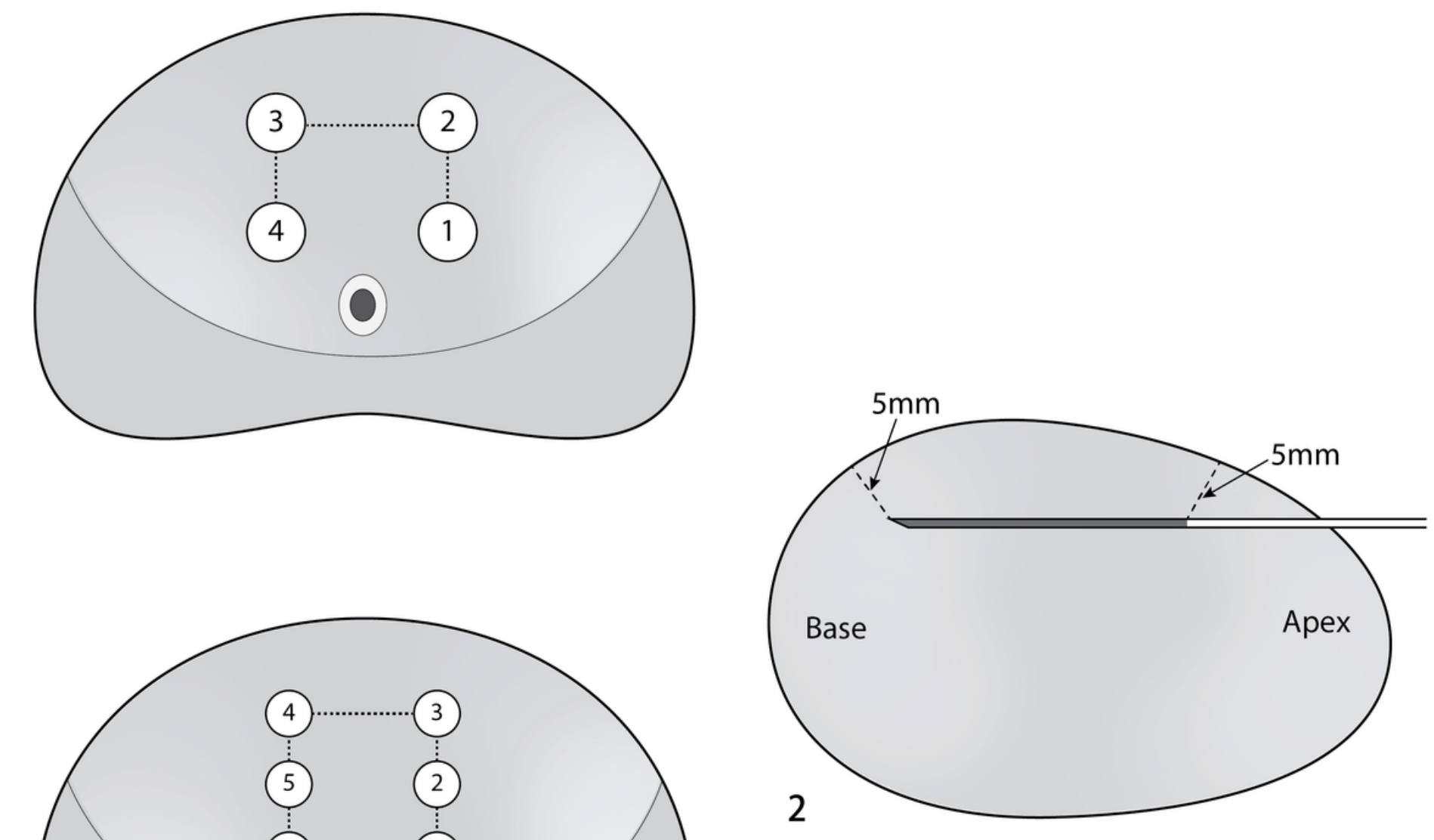

\section{Figure 2}

The schematic of electrode placement during irreversible electroporation procedure.

\section{Supplementary Files}

This is a list of supplementary files associated with this preprint. Click to download.

- SPIRITchecklist.docx 